\title{
Walter Benjamin: \\ o compromisso com a teoria
}

Gustavo Silveira Ribeiro

UFMG

Resumo: Este artigo pretende ler criticamente dois ensaios centrais de Walter Benjamin, "O surrealismo" e "O autor como produtor", à luz de proposições teóricas do pensador hindobritânico Homi K. Bhabha. A questão central que se quer discutir diz respeito às complexas relações que se estabelecem entre estética e política na obra benjaminiana.

Palavras-chave: Teoria estética. Política. Negociação.

1.

Procurando pensar as possibilidades e potencialidades políticas da reflexão teórica, o ensaísta indo-britânico Homi K. Bhabha afirma que, apesar do alto grau de institucionalização acadêmica e pelas relações de poder que mantém com as forças hegemônicas do Ocidente, a teoria, enquanto forma discursiva específica, é capaz de escapar das armadilhas de sua condição e tornar-se instrumento de questionamento e combate. Segundo ele, a carga derrisória que a linguagem teórica pode assumir, desde que assuma sua ambiguidade discursiva e sua natureza híbrida, é o que garante seu alcance verdadeiramente político. Uma das características desse discurso teórico que se coloca como discurso comprometido, ainda segundo Bhabha, diz respeito a sua condição não-dialética, ${ }^{1}$ ou seja, ao fato de que a teoria não tem de colocar-se, necessariamente, ao lado de partidos, ideologias ou conteúdos pré-formados para validar-se no campo político; antes ela deve criar um espaço de tensão permanente de saberes, verdades e posições a fim de instigar novos modos de percepção e entendimento da realidade histórica, cultural e social de um determinado tempo e de um determinado lugar. Nas palavras do próprio autor, trata-se não de repetir termos e posturas dadas, mas de criar, no texto, novas e diferentes instâncias e conteúdos políticos:

A linguagem da crítica é eficiente não porque mantém separados os termos do senhor e do escravo, do mercantilista e do marxista, mas na medida em que ultrapassa as bases de oposição dadas e abre um espaço de tradução: um lugar de hibridismo, para se falar de forma figurada, onde a construção de um objeto político que é novo, nem um nem outro, aliena de modo adequado nossas expectativas políticas, 
necessariamente mudando as próprias formas de nosso reconhecimento do momento da política. ${ }^{2}$

A recusa da síntese e da hierarquia de valores, tomada como princípio da condição política do discurso teórico-crítico, contraria a definição corriqueira do que é o político, e é aí que reside a produtividade das proposições de Bhabha. Habitualmente, qualquer discurso considerado político - seja ele teórico ou não - estrutura-se a partir do princípio binário de oposição de contrários: "nós" e "eles", "oprimidos" e "opressores", "colonizados" e "colonizadores." Sem deixar de reconhecer que essas oposições existem, e sem também deixar de notar as históricas relações de poder e exploração que existem nos mais diversos extratos do tecido social, o autor de Nation and narration propõe, no entanto, uma atuação política (assim como a criação de um campo de intervenção teórica) baseado não na "negação", típica dos discursos e práticas de ordem binária, que precisam obrigatoriamente excluir e silenciar o ponto de vista do outro para validarem a si mesmos, mas na "negociação", termo que sugere a manutenção do conflito e o aprofundamento das tensões sem o apagamento da instância contrária. Segundo o próprio Bhabha, trata-se de uma "temporalidade" distinta, uma espécie de acontecimento: ${ }^{3}$

Quando falo de negociação em lugar de negação, quero transmitir uma temporalidade que torne possível conceber a articulação de elementos antagônicos ou contraditórios: uma dialética sem a emergência de uma História teleológica ou transcendente. ${ }^{4}$

Poucas linhas à frente, referindo-se novamente à teoria, o autor volta a falar em negociação, agora num sentido que considero particularmente interessante a este artigo:

Em tal temporalidade discursiva, o evento da teoria torna-se a negociação de instâncias contraditórias e antagônicas, que abrem lugares e objetos híbridos de luta e destroem as polaridades negativas entre o saber e seus objetos e entre a teoria e a razão prático-política. ${ }^{5}$

O sentido amplo do termo negociação, além das implicações por assim dizer metodológicas arroladas acima, pode também estender-se para inúmeras outras direções, aproveitando sua maleabilidade constitutiva (uma vez que se trata de um conceito oriundo de outra área do conhecimento, a Economia Política, re-alocado na Teoria da Literatura). Um desses deslocamentos possíveis - e que gostaria de propor aqui - é a aproximação dessas reflexões de Bhabha (especialmente as que estão relacionadas à negociação e às potencialidades políticas do discurso teórico) de alguns aspectos da obra do pensador alemão Walter Benjamin. Tomando dois de seus mais 
conhecidos ensaios, "O surrealismo. O último instantâneo da inteligência européia" (1929) e "O autor como produtor" (1934), pretendo expor de que modo os conceitos de Homi Bhabha trabalhados em $O$ local da cultura (com mais ênfase no capítulo "O compromisso com a teoria") podem servir como chave de leitura para alguns aspectos da produção benjaminiana, permitindo surpreender nela tanto uns poucos mecanismos de sua estrutura composicional quanto alguns dos seus significados políticos menos aparentes.

2.

Em "O surrealismo", Benjamin procura fotografar o movimento surrealista em pleno funcionamento (como o subtítulo do texto sugere, inclusive) captando uma imagem multifacetada e complexa do grupo no calor dos acontecimentos políticos e estéticos que marcaram os anos mais fecundos de sua existência. Conhecido pelo gosto provocador, pelas imagens de choque e pela inquietude, o surrealismo, inicialmente, atraiu a curiosidade de Benjamin, entre outras coisas, por seu enorme potencial revolucionário. Antes mesmo de o grupo promover oficialmente uma guinada à esquerda, ${ }^{6}$ Benjamin já notava a carga explosiva de suas propostas e a sua inevitável tendência à causa socialista. O que chama atenção, no entanto, não é o caráter profético da mirada crítica benjaminiana, mas a capacidade do ensaísta em criar, a partir de uma perspectiva de crítico de literatura e arte, um texto eminentemente político. Observe-se o trecho a seguir:

Antes desses videntes e intérpretes de sinais [os surrealistas], ninguém havia percebido de que modo a miséria, não somente a social como a arquitetônica, a miséria dos interiores, as coisas escravizadas e escravizantes, transformavam-se em niilismo revolucionário. ${ }^{7}$

Nele, sem abrir mão da tarefa de esteta, Benjamin faz das suas reflexões teóricas sobre o surrealismo um espaço de combate e militância, tal como - num sentido próximo, porém um pouco distinto - Bhabha dizia ser possível e necessário. Um dos pontos a ser observado no trabalho de Benjamin à luz de proposições do teórico indobritânico e que, segundo creio, é um dos elementos responsáveis pela sua diferença e força política não dogmática, diz respeito ao método de composição textual e, por que não dizer, de pensamento de filósofo alemão. Refiro-me a sua capacidade de articular saberes e verdades mutuamente excludentes em seus textos, transformando-os num 
espaço de negociação epistemológica, para falar com os termos de Homi K. Bhabha (deslocando-os e subvertendo-os, obviamente).

O sentido dessa prática escritural verdadeiramente interdisciplinar pode, num primeiro olhar, parecer apenas ecletismo ou inconsistência teórica de Walter Benjamin. Sua significação decisiva, no entanto, e que responde pela dimensão política que quero observar nesse gesto, tem a ver com o seu poder de não se prender a dogmas ou conteúdos pré-formados ideologicamente, não limitando, assim, seu raio de alcance ao campo de ação e à permanência desses dogmas ou conteúdos. No caso de "O surrealismo", ${ }^{8}$ por exemplo, é possível observar a presença de saberes conflitantes já na escolha vocabular do ensaísta, que no trecho acima citado denota atenção e proximidade de certa tradição de pensamento místico, ao mesmo tempo em que trabalha com conceitos oriundos do marxismo. Ao chamar os escritores e artistas surrealistas de "videntes" e "intérpretes de sinais", ao passo que os coloca como possíveis trabalhadores da causa socialista, Benjamin mistura dois campos do saber muito distintos (o misticismo e a religião, de um lado, e o materialismo histórico e dialético, por outro), e que tradicionalmente não se aproximam, uma vez que tendem à exclusão do outro para se validarem.

Ao invés de mantê-los separados, ou fazê-los chocarem-se para que a perspectiva marxista - considerada científica - prevalecesse, o autor de Um lírico no auge do capitalismo mantém a tensão, utilizando uma área do saber como antídoto aos dogmatismos e limitações da outra. É como se o marxismo viesse desdogmatizar, relativizando-o, o misticismo, e este agisse da mesma forma sobre as constrições ideológicas da tradição marxista. O conceito central do ensaio sobre o surrealismo vem ilustrar, aprofundando-a, essa questão. A "iluminação profana"9 a que se refere Benjamin como síntese das propostas estéticas e políticas do grupo surrealista é fruto desse entrelaçamento entre misticismo e revolução, e sua condição de conceito híbrido é o que garante a carga de estranheza e questionamento que o caracteriza. De "inspiração materialista e antropológica", ${ }^{10}$ a iluminação profana deflagrada pelo movimento liderado por André Breton permitiria, segundo Benjamin, que a percepção sobre os objetos e a história se altere, e que as experiências e sentidos mais recônditos do passado venham à tona. A função política dessa espécie de proposição é clara: fazer ver o mundo com outros olhos, revelar o que está oculto, é um convite à ação transformadora. O curioso (e ao mesmo tempo inovador) é que essa potencialidade política da "iluminação profana" depende da dupla natureza que a informa: ela é 
"iluminação", uma vez que atinge a percepção do leitor/espectador/militante de chofre, nunca se revelando por inteira, ao mesmo tempo em que oferece uma compreensão global do instante histórico-estético e social que a viu nascer; e ela é também profana, já que prescinde da mediação divina (transcendental) para se efetivar, podendo usar a arte, o amor, as drogas e a vivência na cidade como propedêutica. ${ }^{11}$

Se volto mais uma vez aos trechos de "O compromisso com a teoria" anteriormente citados, noto que a prática escritural de Walter Benjamin parece exemplificar, em seus termos e recobrindo objetivos imediatos um tanto diferentes, as proposições de Bhabha sobre a relação teoria e política. Quando ele opõe negociação a negação, pensando no campo atuação do teórico, é possível observar de que modo a manutenção de saberes conflitantes numa mesma tessitura discursiva, como ocorre em "O surrealismo", se mostra como uma possibilidade de concretização, em nível puramente textual, num primeiro momento, dessa proposta. A "negociação de instâncias contraditórias e antagônicas, que abrem lugares e objetivos híbridos de luta"12 descreve à perfeição (guardadas, é claro, as diferenças já colocadas) os caminhos nada óbvios ou lineares do pensamento e da textualidade benjaminiana. Arrisco dizer, ainda, que se uso Bhabha para orientar-me nos labirintos de Benjamin, é bastante plausível imaginar que o caminho contrário foi percorrido pelo teórico hindu: leitor confesso de Walter Benjamin, ele possivelmente transcriou muitas das proposições benjaminianas para seu próprio contexto de enunciação e prospecção teórica.

\section{3.}

Outro aspecto da obra de Walter Benjamin que aqui vai ser lido a partir de categorias de Homi K. Bhabha, a transformação da crítica e da teoria estéticas em instrumento de combate da luta política, tem no ensaio "O autor como produtor", de 1934, um de seus mais fecundos exemplos. Esse texto é, originalmente, uma conferência pronunciada por Benjamin no Instituto para o Estudo do Fascismo, e tem como pressuposto a seguinte noção: "a tendência de uma obra literária só pode ser correta do ponto de vista político quando for também correta do ponto de vista literário." 13 Essa ideia, se desdobrada convenientemente, sugere que o autor pretende mostrar como a verdadeira luta política que se pode travar no campo literário reside antes nas questões de forma do que, como era (e ainda é) comum imaginar em certos círculos críticos, nos problemas de "conteúdo." Isso implica, já de saída, pensar que se 
está lidando com aquelas questões levantadas por Bhabha acerca das relações entre teoria e política. Novamente, é forçoso constatar que Benjamin se entrega ao combate ideológico-político sem renunciar a sua especificidade de crítico de arte, e que esse gesto só faz complexificar a avaliação que se pode fazer de sua atuação como pensador do campo social.

Tratando mais detidamente da obra de seu amigo e companheiro de geração Bertold Brecht, Benjamin parece confirmar a potencialidade do discurso teórico que, segundo a já referida passagem de Bhabha, não distingue nem hierarquiza "entre os objetos da teoria e a razão prático-política."14 Sua análise do chamado "teatro épico" brechtiano, descrito como uma arte do distanciamento, (daí sua condição épica) constituída por interrupções na ação dramática, assertivas metalinguísticas que convocam à reflexão do espectador e lances de humor negro, em que o riso atua como deflagrador do pensamento crítico, é o tempo toda remetida, seja por analogia, seja por referências diretas, ao contexto de combate antifascista que marcou toda a década de 30 do século $\mathrm{XX}$, a última que Benjamin conheceu. Essa atitude crítica, que vai passo a passo ampliando o horizonte da reflexão estética ao inseri-la na História, cumpre dupla função: (1) demarcar a impossibilidade de separação entre formas revolucionárias (aquelas que se propõem a refazer a arte em consonância com o processo de transformação social) e a política propriamente dita; e (2) chamar a atenção especialmente dos escritores e críticos para a ideia, simples à primeira vista, de que a literatura se insere nas formas de produção de seu tempo, ${ }^{15}$ sendo ela também um produto, fruto de elaboração técnica mais ou menos complexa.

Ao chamar atenção justamente para a técnica brechtiana, Benjamin evoca a noção que dá título a sua conferência, a de que o autor (o artista de um modo geral, não só o escritor) é também ele um produtor, inserido nas demandas e lutas das forças produtivas de sua época, não devendo abster-se delas, sob pena de cometer um erro antes de tudo estético, e não ideológico, como as coerções ideológicas do tempo, que constrangiam à esquerda ou à direita, tendiam a pontificar. Com esse gesto, Walter Benjamin a um só tempo reduz e amplia sua questão ao universo da estética, potencializando as energias revolucionárias de suas ideias. Se digo que ele reduz é porque a persistência do trabalho de crítica de literatura e arte, como já dito, faz do próprio discurso teórico política; por outro lado, se digo que se amplia o horizonte das considerações benjaminianas é porque considero que a sua não submissão aos ditames ideológicos e políticos estreitos de seu tempo, que estavam por demais imersos no 
combate político imediato do dia a dia antifascista, é uma forma eficaz de resistência e duração, uma vez que o texto benjaminiano, programaticamente, parece não ter querido restringir-se ao espaço de propaganda e repercussão de conteúdos doutrinários préformados a que a obra de outros teóricos (Brecht incluído) estava destinada. Fecha-se assim, se observamos dessa maneira a obra de Benjamin, o círculo de relações propostas com o pensamento de Homi K. Bhabha: não separando ou hierarquizando arte e política, teoria e ação, o autor de Origem do drama barroco alemão se coloca como militante e intelectual, segundo a breve linhagem proposta por Bhabha daqueles que mantém inabalável o seu compromisso com a teoria.

Resumen: Este artículo pretende leer críticamente dos ensayos centrales de Walter Benjamin, "El surrealismo" y "El autor como productor", a la luz de proposiciones teóricas del pensador hindobritánico Homi K. Bhabha. La cuestión central que se quiere discutir se refiere a las complejas relaciones que se establecen entre estética y política en la obra benjaminiana.

Palabras-clave: Teoría estética. Política. Negociación.

\section{Referências bibliográficas}

BENJAMIN, Walter. Magia e técnica, arte e política. Trad. Sérgio Paulo Rouanet. São Paulo: Brasiliense, 2004.

BENJAMIN, Walter. Um lírico no auge do capitalismo. Trad. José Carlos Martins Barbosa \& Hemerson Alves Baptista. São Paulo: Brasiliense, 2000.

BHABHA, Homi. K. O local da cultura. Trad. Miryam Ávila, Eliana Lourenço \& Gláucia Gonçalves. Belo Horizonte: Ed. UFMG, 1998.

DELEUZE, Gilles \& GUATTARI, Felix. Mil Platôs: capitalismo e esquizofrenia. Trad. Aurélio Guerra Neto \& Célia Pinto Costa. São Paulo: Ed. 34, 1995. (5 volumes)

FALCÃO, Flávia de Carvalho. Arte e política em Walter Benjamin. Belo Horizonte: FAFICH/UFMG, 2001. (dissertação de mestrado)

LÖWY, Michel. A estrela da manhã: marxismo e surrealismo. Trad. Eliana Aguiar. Rio de Janeiro: Civilização Brasileira, 2002.

RIBEIRO, G. S. As lições de literatura: o ensaio benjaminiano e a multiplicidade do saber. In: Revista CRITÉRIO, nº. 8, (www.revista.criterio.nom.br), acessada em 17/07/2008.

SARLO, Beatriz. El crítico literário. In: Siete ensayos sobre Walter Benjamin. Buenos Aires: Fondo de Cultura Económica, 2000. 


\section{Notas}

${ }^{1}$ Entendida aqui a dialética segundo a propuseram Hegel e, posteriormente, Karl Marx. Conforme esses autores, o modelo dialético pressupõe a existência inicial de duas instâncias contrárias que se opõem até a exclusão mútua, que se dá sob a forma da síntese, na qual os opostos se apagam para dar origem a um outro elemento, considerado mais avançado (histórica, ideológica e formalmente) que os termos anteriores.

${ }^{2}$ BHABHA. O local da cultura, p. 51.

${ }^{3}$ Cf. a noção proposta por Gilles Deleuze. In: DELEUZE \& GUATTARI. Mil Platôs: capitalismo e esquizofrenia, p. 13 e ss.

${ }^{4}$ BHABHA. O local da cultura, p. 51.

${ }^{5}$ BHABHA. O local da cultura, p. 51.

${ }^{6}$ O que se deu em 1930, com a publicação de um manifesto assinado por Breton e seus companheiros remanescentes, no qual eles aderiam às propostas de "revolução permanente" defendidas por Leon Trotski, antigo líder da Revolução Russa e, nesse período, dissidente exilado do regime soviético. Cf. LÖWY. A estrela da manhã: marxismo e surrealismo.

${ }^{7}$ BENJAMIN. Magia e técnica, arte e política, p. 25.

${ }^{8}$ Ressalto que em outros trabalhos de Walter Benjamin não abordados aqui dadas as limitações deste texto, esse mesmo elemento interdisciplinar e a mesma vocação para reunir saberes conflitantes pode ser notada. Lembro aqui de "Sobre alguns temas em Baudelaire", por exemplo, em que o autor vai reunir sociologia, moda e urbanismo numa só rede conceitual, ou ainda as conhecidas "Teses sobre o conceito da História", em que vão comparecer indistintamente messianismo judaico e materialismo dialético marxista.

${ }^{9}$ BENJAMIN. Magia e técnica, arte e política, p. 23.

${ }^{10}$ BENJAMIN. Magia e técnica, arte e política, p. 23.

${ }^{11}$ BENJAMIN. Magia e técnica, arte e política, p. 23.

${ }^{12}$ BHABHA. O local da cultura, p. 51.

${ }^{13}$ BENJAMIN. Magia e técnica, arte e política, p. 121.

${ }^{14}$ BHABHA. O local da cultura, p. 51.

${ }^{15}$ BENJAMIN. Magia e técnica, arte e política, p. 128. 